\title{
Infection by Angiostrongylus cantonensis in both humans and the snail Achatina (Lissachatina) fulica in the city of Macapá, in the Amazon Region of Brazil
}

\author{
Tatiane Alves Barbosa ${ }^{1,2}$, Silvana Carvalho Thiengo ${ }^{2 /+}$, Monica Ammon Fernandez ${ }^{2}$, \\ Carlos Graeff-Teixeira ${ }^{3}$, Alessandra Loureiro Morassutti ${ }^{4}$, Fábio Rodrigo Paixão Mourão ${ }^{1}$, \\ Clóvis Omar Sá Miranda', Michel de Moraes Jorge', Liliane Freitas Costa ${ }^{2,5}$, Suzete Rodrigues Gomes ${ }^{2}$ \\ `Secretaria Municipal de Saúde de Macapá, Coordenação de Vigilância em Saúde, Macapá, AP, Brasil \\ 2Fundação Oswaldo Cruz-Fiocruz, Instituto Oswaldo Cruz, Laboratório de Referência Nacional para Esquistossomose-Malacologia, \\ Rio de Janeiro, RJ, Brasil \\ ${ }^{3}$ Universidade Federal do Espírito Santo, Centro de Ciências da Saúde, Núcleo de Doenças Infecciosas, Vitória, ES, Brasil \\ ${ }^{4}$ Instituto de Patologia de Passo Fundo, Passo Fundo, RS, Brasil \\ ${ }^{5}$ Superintendência de Vigilância em Saúde, Laboratório Central de Saúde Pública, Amapá, Brasil
}

In January and February 2019, a malacological survey was conducted in the area surrounding the residence of a 12-year-old child that had contracted cerebral angiostrongyliasis in the municipality of Macapá, capital of the Amapá State, northern Brazil. The serological examination was positive for Angiostrongylus cantonensis infection, the principal etiological agent of this parasitosis. A sample of 54 molluscs was artificially and individually digested for parasitological analysis, containing 38 specimens of Achatina fulica, nine specimens of Bulimulus tenuissimus and seven specimens of Sarasinula linguaeformis. A. fulica was the most abundant mollusc, and the only species infected with A. cantonensis, as well as presenting co-infections with other nematodes. This is the first report of cerebral angiostrongyliasis in the Amazon Region, and the first record of $A$. fulica infected with $A$. cantonensis in Amapá. These findings highlight the potential risks of human angiostrongyliasis, and the need to implement public health measures to control the spread of the disease.

Key words: cerebral angiostrongyliasis - eosinophilic meningitis - giant African snail - snail borne diseases - Aelurostrongylus abstrusus surveillance

Angiostrongyliasis includes parasitic infections caused by metastrongylid nematodes of the genus $A n-$ giostrongylus Kamensky, 1905. The life cycle of this nematode includes rodents and other small wild mammals as the definitive hosts and numerous species of terrestrial and freshwater gastropods, which act as intermediate hosts. ${ }^{(1,2,3,4)}$

Two zoonotic Angiostrongylus species are known to occur in Brazil. One, Angiostrongylus costaricensis Morera \& Céspedes, 1971, causes abdominal angiostrongyliasis, while the other, A. cantonensis (Chen, 1935) causes cerebral angiostrongyliasis. The first is found in mesenteric arteries of the caecum of its definitive host while $A$. cantonensis, known as rat lungworm, is found in pulmonary arteries of the host rodents. In these organs the nematodes eggs are laid and hatch releasing the first stage larvae $\left(\mathrm{L}_{1}\right)$ that are released into the faeces of these animals. ${ }^{(5,6)}$ The $\mathrm{L}_{1}$ larvae are ingested by molluscs, in which they develop in two weeks into either the second $\left(\mathrm{L}_{2}\right)$ and third $\left(\mathrm{L}_{3}\right)$ stages, depending on the environmental conditions. Rodents become infected

doi: 10.1590/0074-02760200115

+ Corresponding author: scarvalhothiengo@gmail.com

(D) https://orcid.org/0000-0002-5547-206X

Received 13 March 2020

Accepted 15 June 2020 through the ingestion of molluscs or plants contaminated with larvae $\left(\mathrm{L}_{3}\right)$ released in the mucus of the mollusc. $(6,7,8)$ Paratenic hosts, such as lizards and crustaceans, may also contribute to the continuity of the life cycle of A. cantonensis. ${ }^{(9)}$ Humans may be infected through the intentional or accidental ingestion of contaminated raw molluscs or the paratenic hosts, or inadequately washed fruit or vegetables with mollusc mucus containing $\mathrm{L}_{3}$ larvae..$^{(7,8,9,10)}$ The parasite does not complete its development in humans, however. ${ }^{(4,11)}$

Cerebral angiostrongyliasis, which is also known as eosinophilic meningitis (EoM), is endemic to certain Asian countries and Pacific Islands. ${ }^{(12)}$ In recent years, distinct species of intermediate and definitive hosts have been found to be infected with $A$. cantonensis outside its original area of occurrence, including countries in the Caribbean region and in South America, such as Brazil. $(4,6,12,13,14)$ In Brazil, cerebral angiostrongyliasis was first reported from Cariacica and Vila Velha, in the State of Espírito Santo, ${ }^{(15)}$ and Recife, capital of the State of Pernambuco, ${ }^{(1,2)}$ although there are now many recorded cases in humans from other regions of the country, including the states of São Paulo ${ }^{(16)}$ and Rio Grande do Sul.(7) Given this context, cerebral angiostrongyliasis is now considered an emerging disease in Brazil, with 35 confirmed and 84 suspected cases. ${ }^{(17)}$ The worldwide dispersal of rodents contributes to the spread of $A$. cantonensis, ${ }^{(16)}$ as does the expansion of the distribution of exotic molluscs, such as Achatina (Lissachatina) fulica Bowdich, 1822, known as the giant African snail. ${ }^{(18)}$ The 
lack of natural enemies and pathogens for this exotic species, combined with the ongoing effects of climate change, contribute to the adaptability of A. fulica to novel environments, which had led to its proliferation in many areas of Brazil. ${ }^{(9,14,18)}$

The present study provides the first report of a case of cerebral angiostrongyliasis in the Brazilian Amazon Region, in the municipality of Macapá, capital of the Amapá State. The study also presents the first record of A. cantonensis larvae infecting the giant African snail, A. fulica, in Amapá.

The epidemiological investigation in Macapá was initiated in August 2018, one month after a 12-year-old child had tested positive for cerebral angiostrongyliasis. The diagnosis was based on a combined ELISA and Western blot to identify the diagnostic antigen of the $31 \mathrm{kDa}$ band. ${ }^{(7)}$

Two months after the diagnosis, the area around the patient's house in the Santa Rita neighborhood of Macapá was surveyed, although no molluscs were found. The patient's mother then reported that the child had had contact with African snails on a vacant lot near the family home, which led to the expansion of the search to five additional sites within an area of approximately $1 \mathrm{~km}^{2}$ around the patient's house, in January and February 2019. The African giant snail was the focus of the epidemiological study, based on the mother's patient report. A sample of 54 molluses was artificially and individually digested for parasitological analysis, containing 38 specimens of A. fulica, nine specimens of Bulimulus tenuissimus (d'Orbigny 1835) and seven specimens of the slug Sarasinula linguaeformis (Semper, 1885). Samples of these species were also fixed and deposited in the mollusc collection of the Oswaldo Cruz Institute (CMIOC) for anatomical analysis and taxonomic identification: $A$. fulica (CMIOC 11799, three specimens; CMIOC 11804, one specimen), B. tenuissimus (CMIOC 11816, one shell), and S. linguaeformis (CMIOC 12388, two specimens). As only few specimens of the Subulina octona (Bruguière, 1789) (CMIOC 11803, six specimens), Allopeas gracile (Hutton, 1834) (CMIOC 12315, five specimens) (both micromolluscs species), Succinea sp. (CMIOC 11802, two juvenile specimens) and Solaropsis rosarium (Pfeiffer, 1849) (CMIOC 11800, one specimen; CMIOC 11801, four specimens) were found, we used these samples just for taxonomic identifications based on morphology.

The parasitological examinations were based on the following protocol (modified from Wallace \& Rosen 1969):(19) the soft tissue was triturated and digested in a $0.7 \%$ solution of $\mathrm{HCl}$ for $6 \mathrm{~h}$, with the resulting liquid being filtered through a Baermann funnel for the isolation of the third stage larvae $\left(\mathrm{L}_{3}\right)$, which were examined under a stereomicroscope. All the larvae with morphological traits of the superfamily Metastrongyloidea were separated for analysis, and those with characteristics of Angiostrongylus spp. were analysed using molecular techniques for species identification. The DNA was extracted by the thermal shock method, with up to 10 larvae, in microcentrifuge tubes, being immersed in liquid nitrogen for $1 \mathrm{~min}$ and then being transferred to a dry bath at $95^{\circ} \mathrm{C}$ for $20 \mathrm{~min}$. This process was repeated three times for each sample.
The polymerase chain reaction (PCR) had a volume of $50 \mu \mathrm{L}$, containing $23.90 \mu \mathrm{L}$ of ultrapure water, $11 \mu \mathrm{L}$ of $10 \%$ trehalose, $5.5 \mu \mathrm{L}$ of 10x PCR reaction buffer, 4.4 $\mu \mathrm{L}$ of $2.5 \mathrm{mM}$ dNTPs, $2.75 \mu \mathrm{L}$ of $50 \mathrm{mM} \mathrm{MgCl}, 1.1 \mu \mathrm{L}$ each of $5 \mu \mathrm{M}$ the forward and reverse primers (Nem 3) from Prosser et al., ${ }^{(20)}$ and $0.25 \mu \mathrm{L}$ of recombinant Taq DNA polymerase (Thermo Fisher Scientific). A $5 \mu \mathrm{L}$ aliquot of the DNA was added to the mixture to reach a final volume of $55 \mu \mathrm{L}$ for each reaction. The PCR products were purified using the Illustra GFX PCR DNA and Gel Band Purification kits (GE Healthcare, Little Chalfont, UK) following the manufacturer's protocol. The purified products were sequenced bidirectionally, using the BigDye Terminator v3.1 Cycle Sequencing kit (Applied Biosystems, California, USA) according to the manufacturer's instructions, on the RPT01A Genomic Platform at the Oswaldo Cruz Institute, in Rio de Janeiro. The sequences obtained in the present study were deposited in GenBank. The chromatograms of the sequences were analysed and edited using Geneious version R9 (http:// www.geneious.com), which resulted in a consensus sequence (contig), which was compared with reference sequences from GenBank using the BLASTn algorithm. ${ }^{(21)}$

The three analysed species in the parasitological investigation, A. fulica, B. tenuissimus and S. linguaeformis, are synanthropic, widely distributed in Brazil and known as natural hosts of $A$. cantonensis. . $^{(5,9,22,23)}$ The invasive giant African snail A. fulica has also being showed to have an important role as intermediate host of this nematode in urban areas because of its extensive presence in many parts of Brazil and its susceptibility to A. cantonensis infection..$^{(1,3,4,7,9)}$ Oliveira et al. ${ }^{(24)}$ examined seven terrestrial mollusc species in the urban zone of the city of São Gonçalo (State of Rio de Janeiro), and two of these species - A. fulica and Bradybaena similaris (Férussac, 1821) - were parasitised by A. cantonensis. In this study, the prevalence of $A$. cantonensis in A. fulica was more than $50 \%$ while in B. similaris, it was $24.6 \%$, and both species were also co-infected with other helminths. In the metropolitan region of Aracaju (Aracaju, Barra dos Coqueiros, Nossa Senhora do Socorro, and São Cristovão), A. cantonensis infection rates were $17.7 \%$ in A. fulica and $4.3 \%$ in B. tenuissimus, ${ }^{(25)}$ which further reinforces the parasitological importance of these molluscs. Specimens of the slug S. linguaeformis have also been found to be infected with both $A$. cantonensis $^{(5)}$ and $A$. costaricensis. The parasitological examination of $50 \mathrm{~S}$. linguaeformis specimens collected in rural Nova Itaberada, a municipality in the southern Brazilian State of Santa Catarina, also revealed infection by $A$. costaricensis in 43 of the 50 slugs. ${ }^{(26)}$

Of the three species analysed by artificial digestion in the present study, only A. fulica was found to be infected with parasites of the superfamily Metastrongyloidea, with 36 of the 38 specimens analysed being infected. Two species of parasite were identified. One was A. cantonensis, identified based on the COI sequences obtained here (571-611 base pairs), which were deposited in GenBank (MN994436, MN994437 and MN994438). These sequences were $100 \%$ similar to those of $A$. cantonensis available in GenBank (MH511542.1 from Brazil, MH511542.1 from Austrália, MK570629.1 from Spain, 
MF000735.1 from United States, and AP017672.1 from Japan). The second parasite species, Aelurostrongylus abstrusus (Railliet, 1898), was identified based on its morphology. Molluscs infected with A. cantonensis and A. abstrusus were collected at three and two of the five study sites, respectively.

This confirms the participation of A. fulica in the life cycle of these nematodes, as already observed in other Brazilian states. ${ }^{(5,6,25)}$ A. fulica has been reported previously in the city of Macapá, in the northern (Brasil Novo neighborhood), central (Central neighborhood), and southern (Pedrinhas neighborhood) zones, ${ }^{(27)}$ although this study did not include parasitological analysis. In northern Brazil, A. fulica and rodents have been found infected with $A$. cantonensis in the Guamá and Jurunas neighborhoods of the city of Belém, ${ }^{(13)}$ although no human infections have been reported.

The discovery of A. abstrusus parasitising A. fulica in Macapá serves as an alert for veterinary medicine, given that this nematode species is a lungworm of cats with a worldwide distribution, ${ }^{(28)}$ including Brazil. ${ }^{(23,29,30)}$ The parasite infection rate recorded in A. fulica in the present study $(94.7 \%$, that is, 36 of the 38 snails examined were infected) was higher than those recorded in previous studies, ${ }^{(24)}$ which highlights the potential role of this exotic species in the transmission of $A$. cantonensis and $A$. abstrusus both of veterinary and public health importance. It is also interesting to note that four A. fulica specimens had a double infection, with $A$. cantonensis being associated with either $A$. abstrusus or a third, yet unidentified nematode, which further reinforce the urgent need for the control of this exotic species in Brazil.

This is the first report of $A$. fulica being infected with A. cantonensis in the Brazilian State of Amapá and the first record of a case of cerebral angiostrongyliasis in the Amazon Region. These findings stress the importance of raising the awareness of public health services with regard to the presence of cerebral angiostrongyliasis in northern Brazil. Preventive measures include the avoidance of contact with potentially infective molluscs, which can be encouraged through health education initiatives. Clearly, further research is urgently needed to map the potential distribution of $A$. cantonensis in Macapá and in other areas in the Amazon Region.

\section{ACKNOWLEDGEMENTS}

To the Genomic Platform - RPT01A (Rede de Plataformas Tecnológicas Fiocruz) for DNA sequencing. We are grateful to Marta Chagas Pinto for assistance with parasitological examination of snails by digestion technique and Arielly Kelly Porfírio de Souza for assistance with the obtention of the COI sequences. We also thank Elivaldo Miranda Nunes for helping in the field work.

\section{AUTHORS' CONTRIBUTION}

COSM, LF, CGT and ALM investigated and diagnosed the index case; TAB, FRPM, MMJ, SRG, SCT and MAF planned and participated in the field expeditions; TAB, SRG, MAF and SCT performed the morphological and parasitological studies of the molluscs and the molecular analysis of the obtained larvae; TAB, SRG, SCT, MAF, CGT and ALM wrote the draft report. All authors reviewed the definitive version.

\section{REFERENCES}

1. Thiengo SC, Maldonado A, Mota EM, Torres EJ, Caldeira R, Carvalho OS, et al. The giant African snail Achatina fulica as natural intermediate host of Angiostrongylus cantonensis in Pernambuco northeast Brazil. Acta Trop. 2010; 115: 194-9.

2. Lima ARMC, Mesquita SD, Santos SS, Aquino ERPD, Rosa LRS, Duarte FS, et al. Alicata disease: neuroinfestation by Angiostrongylus cantonensis in Recife, Pernambuco, Brazil. Arq Neuropsiquiatr. 2009; 67(4): 1093-6.

3. Maldonado Jr A, Simões RO, Oliveira APM, Motta EM, Fernandez MA, Pereira ZM, et al. First report of Angiostrongylus cantonensis (Nematoda: Metastrongylidae) in Achatina fulica (Mollusca: Gastropoda) from Southeast and South Brazil. Mem Inst Oswaldo Cruz. 2010; 105(7): 938-41.

4. Carvalho OS, Scholte RGC, de Mendonça CLF, Passos LKJ, Caldeira RL. Angiostrongylus cantonensis (Nematode: Metastrongyloidea) in molluscs from harbour areas in Brazil. Mem Inst Oswaldo Cruz. 2012; 107(6): 740-6.

5. Ohlweiler FP, Takahashi FY, Guimarães MCA, Gomes SR, Kawano T. Manual de Gastrópodes límnicos e terrestres do Estado de São Paulo associados às helmintoses. Porto Alegre: Redes Editora; $2010.224 \mathrm{pp}$.

6. Thiengo SC, Simões RO, Fernandez MA, Maldonado Jr A. Angiostrongylus cantonensis and Rat lungworm disease in Brazil. Hawaii J Med Public Health. 2013; 72(6): 18-22.

7. Morassutti AL, Thiengo SC, Fernandez M, Sawanyawisuth K, Graeff-Teixeira C. Eosinophilic meningitis caused by Angiotrongylus cantonensis: an emergent disease in Brazil. Mem Inst Oswaldo Cruz. 2014; 109(4): 399-407.

8. Giraldo A, Garzón C, Castillo A, Cordoba-Rojas DF. Confirmation of the presence of Angiostrongylus cantonensis in lung tissue of the African giant snail (Lissachatina fulica) in Colombia. Rev Infectio. 2019; 23(2): 129-32.

9. Fischer ML, Milléo LC. O caramujo gigante africano Achatina fulica no Brasil. Champagnat; 2010. 270 pp.

10. Bonetti VC, Graeff-Teixeira C. Angiostrongylus costaricensis and the intermediate hosts: observations on elimination of L3 in the mucus and inoculation of L1 through the tegument of molluscs. Rev Soc Bras Med Trop. 1998; 31: 289-94.

11. Alicata JE. Angiostrongylus cantonensis (Nematoda: Metastrongylidae) as a causative agent of eosinophilic meningitis of man in Hawaii and Tahiti. Can J Zool. 1962; 40: 5-8.

12. Moreira VLC, Giese EG, Melo FTV, Simões RO, Thiengo SC, Maldonado Jr A, et al. Endemic angiostrongyliasis in the Brazilian Amazon: natural parasitism of Angiostrongylus cantonensis in Rattus rattus and $R$. novergicus and sympatric giant African land snails Achatina fulica. Acta Trop. 2013; 125: 90-7.

13. Alicata JE. The discovery of Angiostrongylus cantonensis as a cause of human Eosinophilic meningitis. Parasitol Today. 1991; 7(6): 151-3.

14. Kim JR, Hayes KA, Yeung NW, Cowie RH. Diverse gastropod hosts of Angiostrongylus cantonensis, the Rat Lungworm, globally and with a focus on the Hawaiian Islands. PLoS One. 2014; 9(5): e94969.

15. Caldeira RL, Mendonça CLGF, Gouveia CO, Lenzi HL, GraeffTeixeira C, Lima WS, et al. First record of molluscs naturally infected with Angiostrongylus cantonensis (Chen, 1935) (Nematoda: Metastrongylidae) in Brazil. Mem Inst Oswaldo Cruz. 2007; 102(7): 887-9. 
16. Espírito-Santo MCC, Pinto PLS, Mota DJGD. The first case of Angiostrongylus cantonensis eosinophilic meningitis diagnosed in the city of São Paulo, Brazil. Rev Inst Med Trop. 2013; 55(2): 129-32.

17. Cunha MCR. Meningite eosinofílica: relato de caso. RBAC. 2017; 49(2): 213-5.

18. Civeyrel L, Simberloff D. A tale of two snails: is the cure worse than the disease? Biodivers Conserv. 1996; 5(10): 1231-52.

19. Wallace CD, Rosen L. Techniques for recovering and identifying larvae of Angiostrongylus cantonensis from molluscs. Malacologia. 1969; 7(2-3): 427-38.

20. Prosser SW, Velarde-Aguilar MG, León-Règagnon V, Hebert PDN. Advancing nematode barcoding: a primer cocktail for the cytochrome c oxidase subunit I gene from vertebrate parasitic nematodes. Mol Ecol Resour. 2013; 13: 1108-15.

21. Altschul SF, Gish W, Miller W, Myers EW, Lipman DJ. Basic local alignment search tool. J Mol Biol. 1990; 215: 403-10.

22. Simone LRL. Land and freshwater molluscs of Brazil. São Paulo: EGB FAPESP; 2006. 390 pp.

23. Capinera JL. Biology and food habits of the invasive snail $\mathrm{Al}$ lopeas gracile (Gastropoda: Subulinidae). Fla Entomol. 2017; 100(1): 116-23.

24. Oliveira APM, Gentile R, Maldonado Jr A, Torres EJL, Thiengo $\mathrm{SC}$. Angiostrongylus cantonensis infection in molluscs in the municipality of São Gonçalo, a metropolitan area of Rio de Janeiro, Brazil: role of the invasive species Achatina fulica in parasite transmission dynamics. Mem Inst Oswaldo Cruz. 2015; 110(6): 739-44.
25. Ramos-de-Souza J, Thiengo SC, Fernandez MA, Gomes SR, Antônio JC, Clímaco MC, et al. First records of molluscs naturally infected with Angiostrongylus cantonensis (Nematoda: Metastrongyloidea) in Northeastern Brazil, including new global records of natural intermediate hosts. Rev Inst Med Trop São Paulo. 2018; 60: 1-7.

26. Laitano AC, Genro JP, Fontoura R, Branco SSL, Maurer RL, Graeff-Teixeira C, et al. Report on the ocurrence of Angiostrongylus costaricensis in southern Brazil, in a new intermediate host from the genus Sarasinula (Veronicellidae, Gastropoda). Rev Soc Bras Med Trop. 2001; 34(1): 95-7.

27. Oliveira JCS, Gonçalves TS, Monteiro PR, Saraiva IO, Vasconcelos HCG. Ocorrência de Achatina fulica (Mollusca, Pulmonata: Achatinidade) em três bairros de Macapá, Amapá. Biota Amazônia. 2012; 2(2): 78-81.

28. Pereira PR, Argenta FF, Rolim VM, Oliveira EC, Pavarini LS, Pavarini SP, et al. Estudo retrospectivo de pneumonia por Aelurostrongylus abstrusus em gatos. Acta Sci Vet. 2017; 45: 1433.

29. Thiengo SC, Fernandez MA, Torres EJ, Coelho PM, Lanfredi RM. First record of a nematode Metastrongyloidea (Aelurostrongylus abstrusus larvae) in Achatina (Lissachatina) fulica (Mollusca, Achatinidae) in Brazil. J Invertebr Pathol. 2008; 98: 34-9.

30. Andrade-Porto SM, Souza KCP, Cárdenas MQ, Roque RA, Pimpão DM, Araújo CS, et al. Occurrence of Aelurostrongylus abstrusus (Railliet, 1898) larvae (Nematoda: Metastrongylidae) infecting Achatina (Lissachatina) fulica Bowdich, 1822 (Mollusca: Gastropoda) in the Amazon Region. Acta Amazonica. 2012; 42(2): 245-50. 